\title{
Forced degradation studies on Naratriptan HCL by High Performance Liquid Chromatography
}

\author{
Vaibhav Kulkarni ${ }^{*}$, Kiran Sonawane ${ }^{2}$ \\ ${ }^{1,2}$ Department of Quality Assurance, SVB's College of Pharmacy, Dombivli (E) (MS), \\ India.
}

\begin{abstract}
Naratriptan HCL is Anti Migraine Drug, the forced degradation studies of Naratriptan HCL were performed under acidic, basic, neutral, photolytic, and dry heat by High Performance Liquid Chromatography (HPLC). The drug was found to be unstable in alkaline medium as well as acidic medium compared to neutral conditions. The drug showed degradation in $8 \mathrm{hr}$ at $60^{\circ} \mathrm{C}$ when the studies were carried under $0.01 \mathrm{~N} \mathrm{NaOH}$, while drug showed the degradation in $0.01 \mathrm{~N}$ HCL when it was subjected to reflux for 2 hours at $60^{\circ} \mathrm{C}$. Same retention time of degradant was also observed in neutral conditions, when drug was allowed to reflux in water for 8 hours at $100^{\circ} \mathrm{C}$. Drug was found to be stable in $50 \% \mathrm{H} 2 \mathrm{O} 2$. Drug was also found to be stable in other conditions such as photolytic and dry heat. Suitable mobile phase was developed and separation of drug and degradant was achieved using isocratic elution. The method was developed on C-18 column using acetonitrile : water as a mobile phase in the ratio of 50:50, 100 $\mu \mathrm{l}$ of the sample were injected in the system for chromatographic Analysis, the selected wavelength was $223 \mathrm{~nm}$ and flow rate was $1 \mathrm{ml} / \mathrm{min}$.
\end{abstract}

Key words: Naratriptan HCL, HPLC, isocratic elution, acetonitrile: water, C-18 column. 


\section{Introduction}

The ICH guidelines indicates that stress testing is designed to help, "Determine the intrinsic stability of the molecule by establishing the degradation pathways in order to identify the likely degradation products and to validate the stability indicating power of analytical procedure used".

Stress testing is a critical component of drug development. By generating the key test samples (i.e. partially degraded drug sample stress under various conditions) predictive degradation information can be obtained early in process and can be of significant value to a drug company in terms of time and money. In addition stress testing can help in the selection of more stable drug substance, salt form and drug formulation. The degradation samples should be monitored by appropriate HPLC methods for any change in chromatographic purity profiles as well as for recovery of drug substance. Specified stress conditions should result in approximately 10-20\% degradation of drug substance or represents a reasonable maximum condition achievable for drug substance. If no degradation is observed under the conditions, it is recommended that stress testing should be stopped. The analytical method developed need to separate degradants observed on stability; therefore it is critical that the stress testing model should be realistic. Excessive stress will lead to decomposition beyond primary degradation components. This level of stress will cause unnecessary method development for separation of components that will never be observed upon storage according to ICH guidelines. For the degradation, all samples generated should be stored at or below $5^{\circ} \mathrm{c}$ to preserve kinetic points until HPLC screening analysis can be performed. Key samples can then be used to optimize the analytical methodologies. It is important that these key predictive samples do not continue to react with time, since it would make yield no predictive secondary degradants. These additional variables would make method development (especially peak tracking) extremely difficult in optimization phase.[3,5,6]

\section{Acid / Base Stress Testing}

Acid/Base stress testing is performed to force the degradation of drug substance to its primary degradation products by exposure to acidic and basic conditions over time. Functional groups likely to introduce acid/base hydrolysis are amides (lactams), esters (lactones), carbamates, imides, imines, alcohols (epimerization for chiral centers) and aryl amines. To initiate acid/base stability studies, a preliminary solubility screen of the drug substance is performed. Solubility of at least $1 \mathrm{mg} / \mathrm{ml}$ in $1 \mathrm{~N}$ acidic and $1 \mathrm{~N}$ basic conditions is recommended for the acid/base stress testing; however, conditions less than $1 \mathrm{mg} / \mathrm{ml}$ can be used if solubility is an issue. In some cases, a co-solvent may be necessary to achieve the target concentration. One should carefully 
investigate the chemical composition of the drug substance and take care not to use a co solvent that may react with it.

Acid/base reaction should be initiated at room temperature in the absence of light. Heat should be avoided where possible, because this introduces a second variable. If no degradation is observed at room temperature, then temperature can be increased. The hydrolytic degradation of new drug under acidic and alkaline condition can be studied by refluxing the drug in $0.1 \mathrm{~N}$ $\mathrm{HCl} / \mathrm{NaOH}$. If reasonable degradation is seen, testing can be stopped at this point. However in case no degradation is seen under these conditions the drug should reflux in acid /alkali of higher strength and for longer duration of time. Alternatively if total degradation is seen after subjecting drug to initial condition, acid/alkali condition can decrease along with decrease in reaction temperature. The acid/base stress conditions should result in approximately 10-20\% degradation of the drug substance or represent a reasonable maximum condition achievable. If this level of degradation is not achieved, additional hydrolysis experiments should be performed at no more than $70^{\circ} \mathrm{C}$. Going above this level of stress is not recommended for typical drug substance materials. Excessive acid/base stress will produce no predictive samples and will lead to unnecessary effort in the HPLC method development.

\section{Neutral Stress Testing}

Stress testing under neutral condition can be started by refluxing the drug in water for $12 \mathrm{hr}$. Refluxing time should increase as per the degradation obtained in 12 hours.

\section{Oxidative Stress Testing}

Drug substance functional groups that are susceptible to oxidation reactions include heteroatom (nitrogen: $\mathrm{N}$-oxides and sulfur: sulfoxide and sulfones), benzylic sites, and aldehydes and ketones. To prepare for oxidative degradation study, a preliminary solubility analysis of drug substance should be performed. Oxidative purposeful degradation studies typically require solubility of approximately $1-10 \mathrm{mg} / \mathrm{ml}$ in unbuffered conditions to achieve reasonable levels of degradation. In test for oxidation, it is suggested to use hydrogen peroxide in the concentration range of 3 to $50 \%$. In some drugs, extensive degradation is seen when exposed to $3 \%$ of hydrogen peroxide for a very short period of time at room temperature. In other cases exposure to high concentration of hydrogen peroxide, dose not causes any significant degradation. The behavior is on expected lines, as some drugs are in fact oxidisable, while others are not.

\section{Photolytic Degradation}

The goal of the photo stability studies is to force the degradation of drug substances via UV and fluorescent conditions over time to determine the primary degradation products. UV and visible lights are the most energetic electromagnetic radiation sources to which pharmaceutical drug substances and drug products are typically exposed. A molecule absorbs light when an 
absorption band exist that overlaps to some extent with the incident light energy and a valence electron in the relevant chromophore is raised to an excited state. Light stress conditions can also induce photo oxidation by free radical mechanisms. Functional groups likely to introduce drug photo reactivity are as follows: carbonyl, nitro aromatic, $\mathrm{N}$-oxide, alkenes, aryl chlorides, weak $\mathrm{C}-\mathrm{H}$ and $\mathrm{O}-\mathrm{H}$ bonds, sulfides and polyenes. There are two types of studies used in pharmaceutical photo stability testing: stress testing (purposeful degradation) and confirmatory testing. Purposeful degradation is used to evaluate to overall photosensitivity of the material (unprotected drug substance and drug product) for method development purpose and/or degradation pathway elucidation.

UV light: The photolytic studies should be carried out by exposure to light using either a combination of cool white and UV fluorescent light and if decomposition is not seen the intensity should be increased by 5 times. In case still no degradation takes place, the drug can be declared photo stable.

Sunlight: the photolytic studies should cover the exposure of drug solution to sunlight. The exposure period ranges from few hours to several months. The photolytic studies are carried out at room temperature.

\section{Thermal and Thermal/Humidity Stress Testing}

The goal of thermal and thermal/humidity studies is to force the degradation of drug substance Over time to determine the primary thermal and/or humidity degradation products. To evaluate Stability utilizing evaluated temperature stress conditions are selected based on a conservative estimate of the Arrhenius expression - a quantitative relationship of reaction rate and temperature using average activation energy. Based on this estimate, a $10{ }^{\circ} \mathrm{C}$ increase in temperature results in doubling of the reaction rate and decrease in the reaction time by factor of 2 . Using this rule of thumb, 1 year at $30{ }^{\circ} \mathrm{C}$ is equivalent to 3 week at $70{ }^{\circ} \mathrm{C}$. The starting stress conditions with humidity levels are $70{ }^{\circ} \mathrm{C} / 30 \% \mathrm{RH}$ (ambient humidity) and $70{ }^{\circ} \mathrm{C} / 75 \%$ $\mathrm{RH}$. The starting conditions are modified if compound undergoes a change in physical format or below this elevated temperature. According to the thermal/humidity stress testing conditions selected samples are placed into appropriate ovens. If humidity ovens are capable of $70{ }^{\circ} \mathrm{C} / 30 \% \mathrm{RH}$ and $70{ }^{\circ} \mathrm{C} / 75 \% \mathrm{RH}$ are not available, saturated salt solutions contained in desiccators can be used to control humidity accurately. These conditions are useful particularly for high potency drug substance compounds for which sample must be contained. Saturated $\mathrm{NaCl}$ solution used to obtain conditions for $75 \% \mathrm{RH}$ at $70^{\circ} \mathrm{C}$ and saturated $\mathrm{MgCl} 2$ solution is to be used to obtain the condition of $30 \% \mathrm{RH}$ at $70^{\circ} \mathrm{C}$.

\section{Drug Profile}

Naratriptan is chemically known as N-methyl- 3-(1- methyl-4- piperidinyl)-1H-indole- 5ethanesulfonamide mono hydrochloride. It is a novel second generation triptan antimigrane used for the treatment of the acute migraine attacks and the symptoms of migraine, including severe,throbbing headaches that sometimes are accompanied by nausea and sensitivity to sound or light. Tablets for oral administration contain 1.11 or $2.78 \mathrm{mg}$ of naratriptan hydrochloride equivalent to 1 or $2.5 \mathrm{mg}$ of naratriptan, respectively. 


\section{Methods}

\section{Acid Degradation}

$10 \mathrm{mg}$ of Naratriptan HCL $+10 \mathrm{ml}$ of $0.1 \mathrm{~N} \mathrm{HCl}$ were prepared at the time of injection (zero sample). Similar studies were performed at various temperatures to see the degradation behavior of drug and optimum conditions were selected in which drug showed 10-20\% degradation. All the above samples were diluted with methanol (AR grade) up to $100 \mathrm{ml}$ in a volumetric flask. $1 \mathrm{ml}$ aliquots were taken from above mentioned samples and were diluted up to $10 \mathrm{ml}$ by mobile phase. Volume of $100 \mu \mathrm{l}$ was injected into the system for chromatographic analysis.

\section{Base Degradation}

$10 \mathrm{mg}$ of Naratriptan HCL $+25 \mathrm{ml}$ of $0.1 \mathrm{~N} \mathrm{NaOH}$ was prepared at the time of injection (zero sample), (10 $\mathrm{ml}$ of $0.1 \mathrm{~N} \mathrm{HCl}$ was added to neutralize the base) All the above samples were diluted with methanol (AR grade) up to $100 \mathrm{ml}$ in a volumetric flask. $1 \mathrm{ml}$ aliquot was taken from above mentioned samples and were diluted up to $10 \mathrm{ml}$ by mobile phase. Volume of $100 \mu \mathrm{l}$ was injected into the system for chromatographic analysis and results of all four chromatograms were compared to see whether degradation occurred or not.

\section{Oxidative Degradation}

Peroxide studies were carried out in two ways $10 \mathrm{mg}$ of Naratriptan HCL $+6 \%$ H $2 \mathrm{O} 2$. These samples were kept in a clean beaker in a dark room for 12 \&amp; 24 hours. Zero samples of above samples were also prepared. Similar studies were also performed on $10 \%$ and $50 \%$ peroxide for same period of time. All the above samples were diluted with methanol (AR grade) up to $100 \mathrm{ml}$ in a volumetric flask.1 ml aliquot was taken from above mentioned samples and were diluted up to $10 \mathrm{ml}$ by mobile phase. Volume of $100 \mu \mathrm{l}$ was injected into the system for chromatographic analysis and results of all four chromatograms were compared to see whether degradation occurred or not.

\section{Neutral Degradation}

Naratriptan HCL was accurately weighed and was transferred to labeled round bottom flask (RBF) Following samples were prepared for the degradation studies. $10 \mathrm{mg}$ of Naratriptan $\mathrm{HCL}+10 \mathrm{ml}$ water was refluxed on heating mantle for 8 hours.

\section{Dry Heat Degradation}

Standard Naratriptan HCL was placed in an oven at $60^{\circ} \mathrm{C}$ for 24 and 48 hours to study dry heat degradation. . Zero sample of standard Naratriptan HCL was also prepared. Both the samples were diluted with methanol (AR grade) up to100 $\mathrm{ml}$ in a volumetric flask. $1 \mathrm{ml}$ aliquots were taken from above mentioned samples and were diluted up to $10 \mathrm{ml}$ by mobile phase. Volume of $100 \mu \mathrm{l}$ was injected into the system for chromatographic analysis and results of both chromatograms were compared to see whether degradation occurred or not. 


\section{Photolytic Degradation}

Photo stability was performed by placing $10 \mathrm{mg}$ of Naratriptan HCL in daylight for 24 and 48 hours. Zero sample of standard Naratriptan HCL was also prepared. Both the samples were diluted with methanol (AR grade) up to $100 \mathrm{ml}$ in a volumetric flask. $1 \mathrm{ml}$ aliquots were taken from above mentioned samples and were diluted up to $10 \mathrm{ml}$ by mobile phase. Volume of $100 \mu \mathrm{l}$ was injected into the system for chromatographic analysis and results of both chromatograms were compared to see whether degradation occurred or not.

\section{Results and Discussion}

\section{Optimization of Procedure}

The procedure was optimized with a view to develop a stability indicating assay method. Pure drug along with its degraded product were injected and HPLC was carried out in different solvent systems. Initially, methanol and water in ratio of 40:60 was tried which showed acceptable retention time, but there was slight tailing in a peak was observed. Also different ratios of same mobile phase were tried but yet no resolution was obtained. Later, methanol was replaced by acetonitrile and mobile phase of acetonitrile: water in various concentrations was tried. The acetonitrile: water in ratio of 40:60 was tried which showed acceptable retention time, with good resolution between drug and the degradant. With the experience of the characteristics of the above mobile phases, finally acetonitrile: water in the ratio of 50:50 was tried which resulted in excellent resolution and a typical peak was obtained. The retention time of the drug was 5.0 minutes and that of the degradant at 5.5 minutes. Asymmetry factor for Naratriptan HCL drug was less than 2 and the resolution in presence of the degradation product was satisfactory. Hence, this mobile phase was finally selected for validation purpose and stability studies

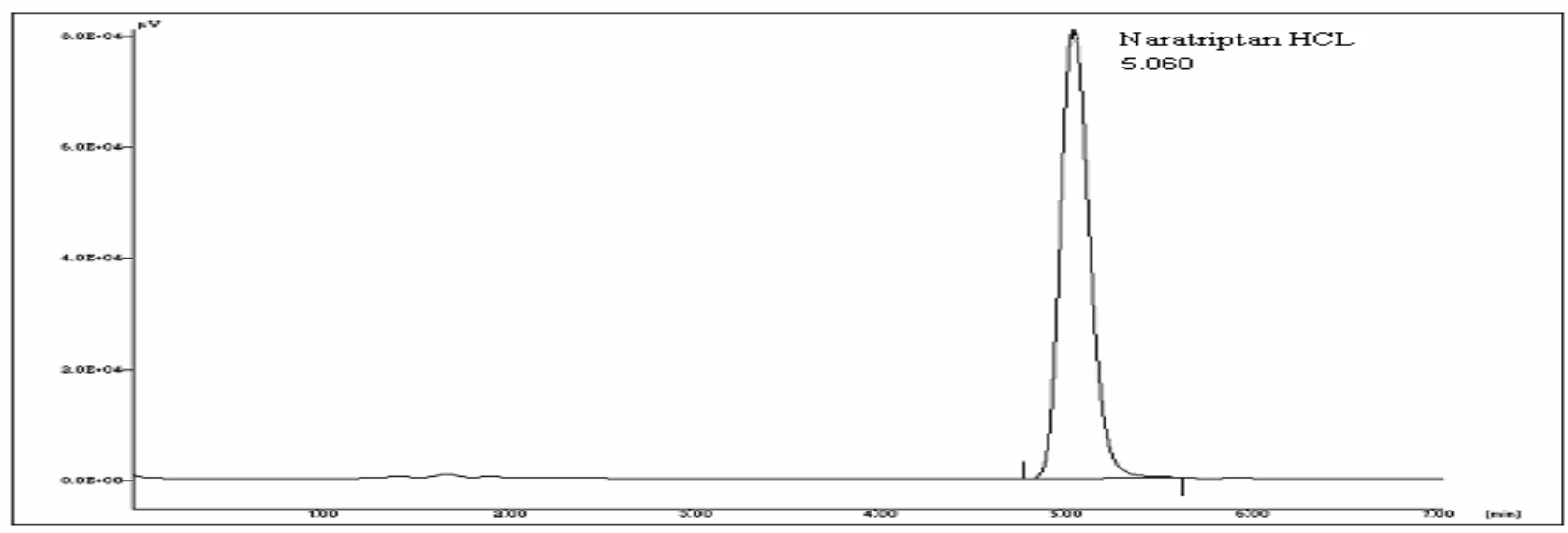

Figure 1.Chromatogram of standard Naratriptan HCL 


\section{Acidic Degradation}

Naratriptan $\mathrm{HCL}$ was found to be very labile in acid. The drug on refluxing in $0.1 \mathrm{~N} \mathrm{HCl}$ resulted in formation of degradation peaks. Almost $70 \%$ degradation was observed in $0.1 \mathrm{~N} \mathrm{HCl}$ when kept at reflux for 8 hours. Therefore, further studies were conducted in milder acidic condition at $0.01 \mathrm{~N} \mathrm{HCl}$ at reflux condition for 8 hours. The drug on refluxing in $0.01 \mathrm{~N} \mathrm{HCl}$ for 8 hours resulted in formation of major degradant product so the time of reflux was reduced to 2 hours and around $25 \%$ of degradation was observed in this condition. The retention time for drug was $\sim 5.0 \mathrm{~min}$ and that of degradant was $\sim 5.5$ $\min$.

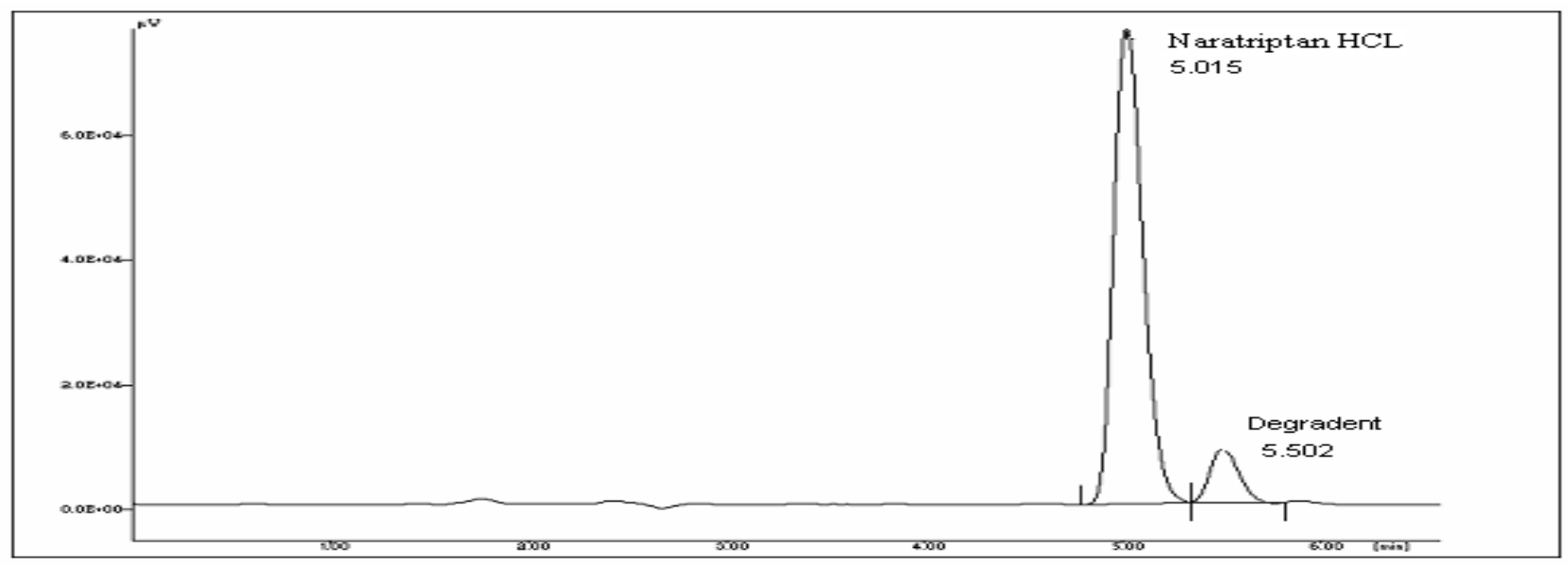

Figure 2. Chromatogram of Naratriptan HCL in $0.01 \mathrm{~N} \mathrm{HCL}$

\section{Basic Condition}

Naratriptan HCL was found to be very labile in alkali. The drug on refluxing in $0.1 \mathrm{~N} \mathrm{NaOH}$ resulted in formation of degradation peaks. Almost $70 \%$ degradation was observed in $0.1 \mathrm{~N}$ $\mathrm{NaOH}$ when kept at reflux for 8 hours. Therefore, further studies were conducted in milder alkali condition at $0.01 \mathrm{~N} \mathrm{NaOH}$ for $60^{\circ} \mathrm{C}$ for 8 hours, $20 \%$ of degradation was observed in this condition. As shown in figure 10, degradation of drug in this condition resulted in rise of one minor degradation product at $\sim 5.6 \mathrm{~min}$. The drug was highly unstable in alkaline medium as compared to acidic conditions.

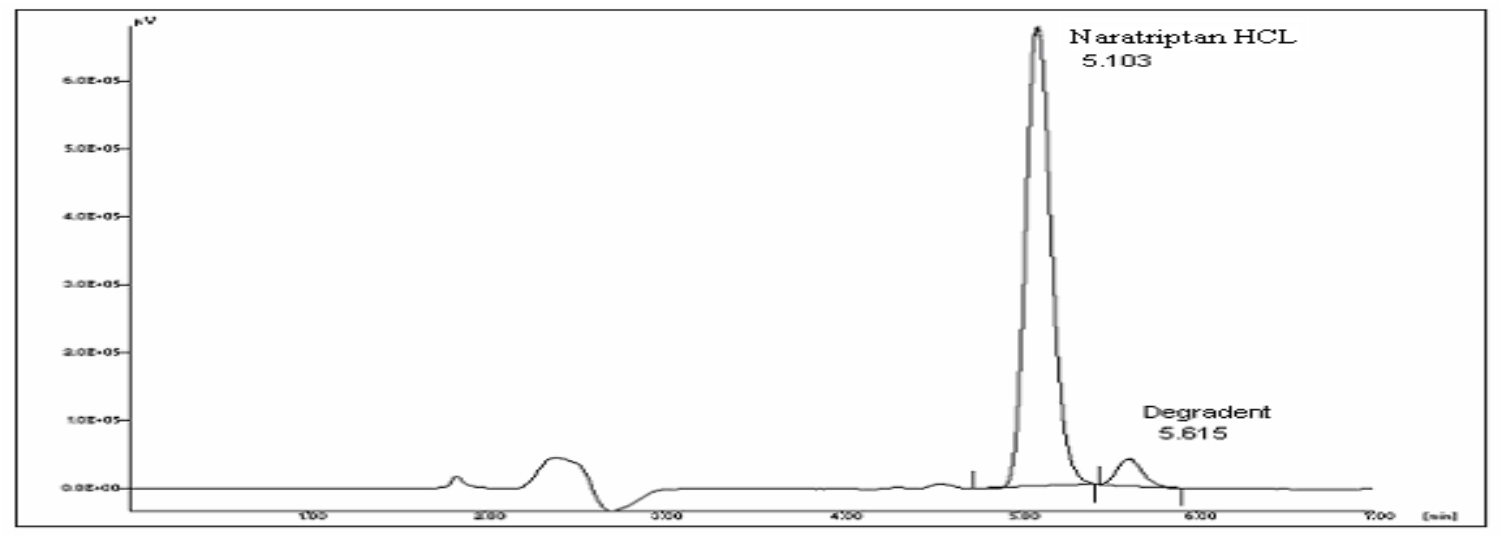

Figure 3. Chromatogram of Naratriptan HCL in $0.01 \mathrm{~N} \mathrm{NaOH}$ 


\section{Neutral condition}

Degradation of drug was seen in neutral conditions after refluxing for 8 hours at $100^{\circ} \mathrm{C}, 35 \%$ of degradation was observed in this condition. The degradant peak was observed at retention time of $\sim 5.60$ and that of drug at $\sim 5.0$. The retention time of degradant peak in acid, alkali and water was found to be similar.

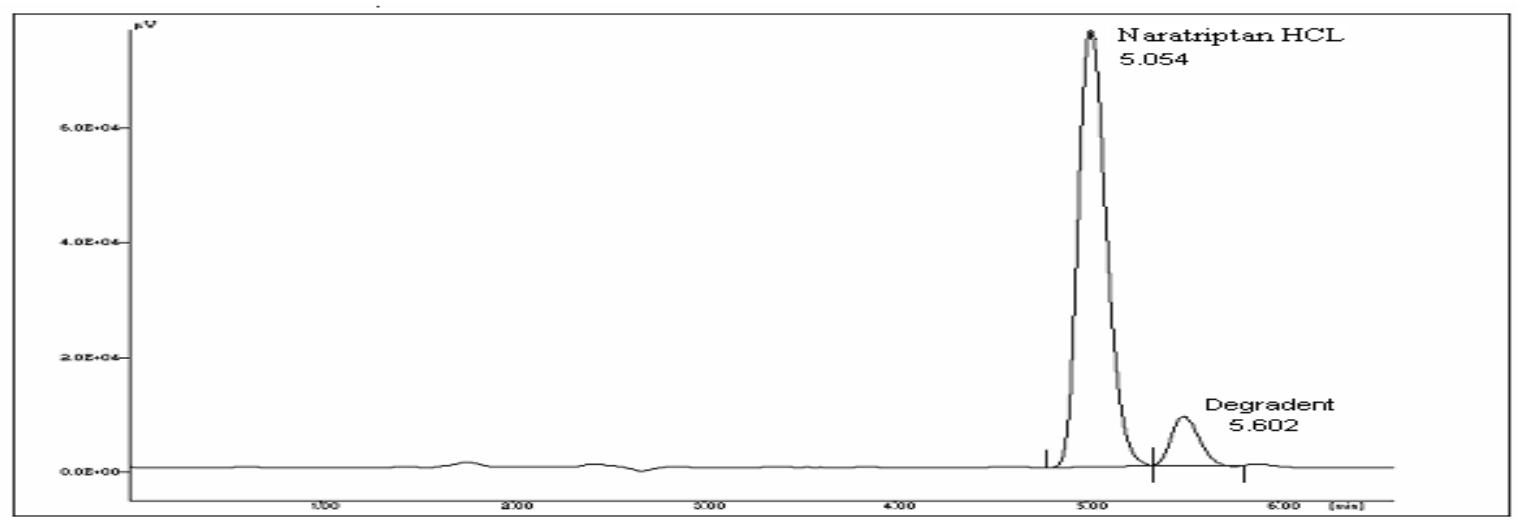

Figure 4. Chromatogram of Naratriptan HCL in neutral conditions (Reflux for 8 hour at $\left.100^{\circ} \mathrm{C}\right)$.

\section{Oxidative degradation}

Naratriptan HCL was found to be stable in $50 \% \mathrm{H} 2 \mathrm{O} 2$ at room temperature for 24 hours so time period was increased to 48 hours and chromatograms showed no degradation behavior. Drug was declared to be stable at above-mentioned conditions

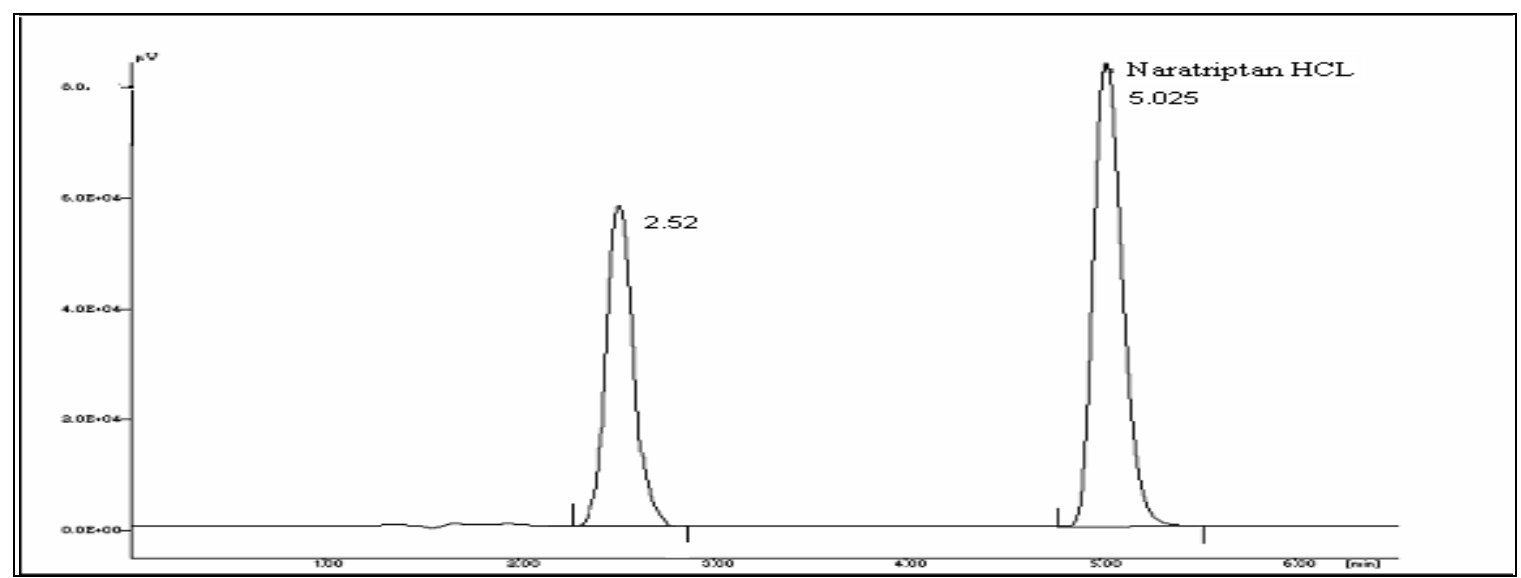

Figure 5. Chromatogram of Naratriptan $\mathrm{HCL}$ in $50 \% \mathrm{H} 2 \mathrm{O} 2$ (Naratriptan $\mathrm{HCL}+\mathrm{H}_{2} \mathrm{O}_{2}+$ water 


\section{Dry Heat}

Naratriptan HCL was subjected to dry heat conditions at $60^{\circ} \mathrm{C}$ for 24 hours, and chromatogram of HPLC showed no degradation peak so time period was increased from $24 \mathrm{hrs}$ to 48 hours and chromatograms showed no degradation behavior. It was concluded that drug was stable in these condition.

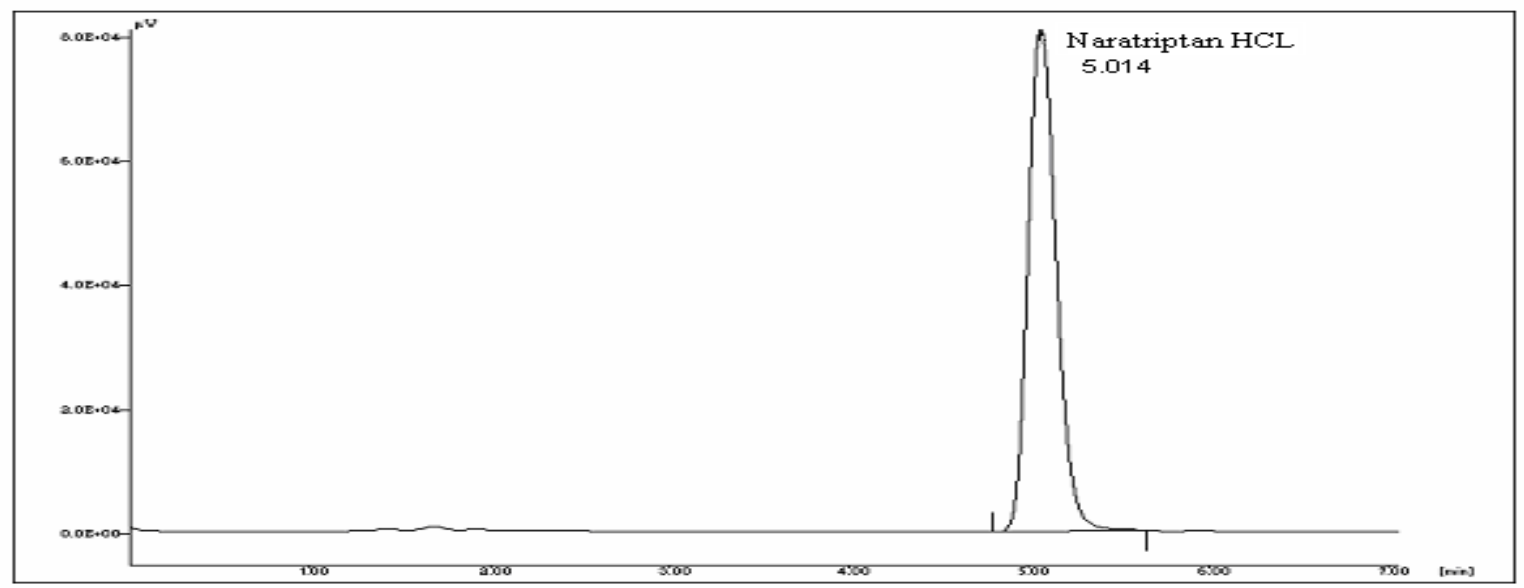

Figure 6. Chromatogram of Naratriptan HCL for dry heat

\section{Photolytic degradation}

The drug sample was subjected to sunlight for 24 hours in a petri dish. The drug was found to be stable. The area of sample subjected to sunlight was found to be similar when compared with standard area of Naratriptan HCL. So time period was increased to 48 hours and chromatograms showed degradation of drug in this condition resulted in rise of one degradation peak at $\sim 5.802 \mathrm{~min}$.

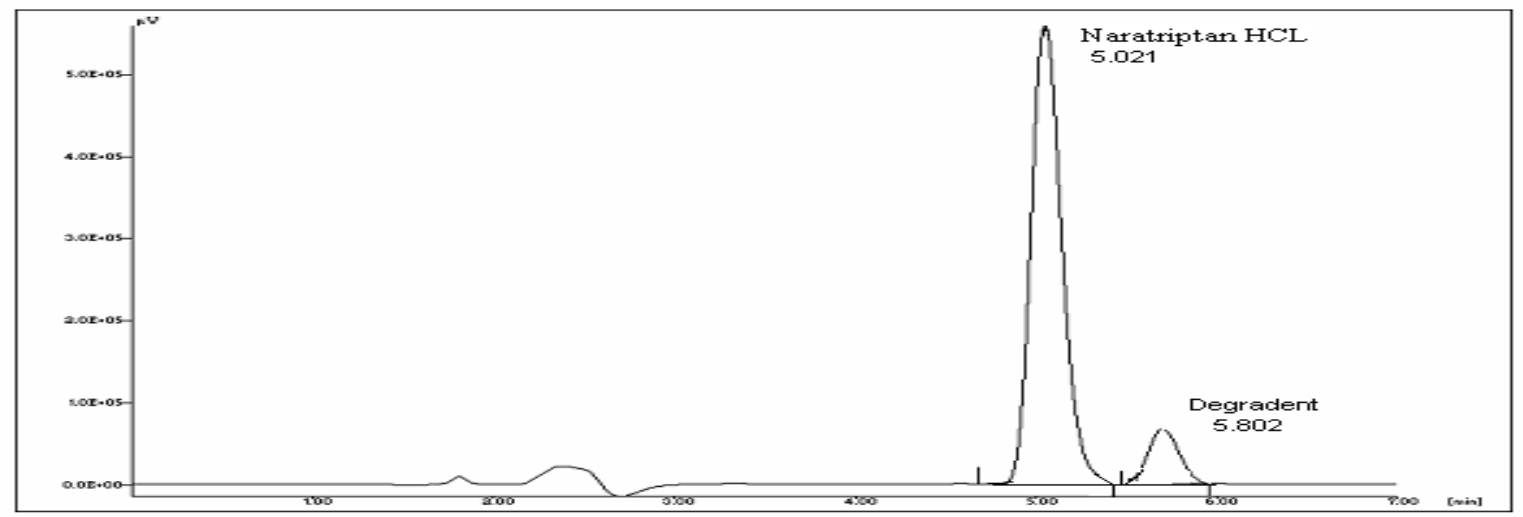

Figure 7. Chromatogram of Naratriptan HCL for photo stability testing 
Table 1. Forced Degradation studies on Naratriptan HCL

\begin{tabular}{|c|c|c|c|c|}
\hline Condition & $\begin{array}{l}\text { Retention } \\
\text { time of } \\
\text { Drug } \\
\text { (mins) }\end{array}$ & $\begin{array}{l}\text { Retention } \\
\text { time of } \\
\text { Drug } \\
\text { (mins) }\end{array}$ & $\begin{array}{l}\% \\
\text { Degradation }\end{array}$ & Remarks \\
\hline $\begin{array}{l}\text { Acidic } \\
0.01 \mathrm{~N} \mathrm{HCl} \text {, reflux } \\
\text { for } 2 \mathrm{hrs} \text { at } 60^{\circ} \mathrm{C} \text {. }\end{array}$ & 5.015 & 5.502 & $25 \%$ & Unstable \\
\hline $\begin{array}{l}\text { Basic } \\
0.01 \mathrm{~N} \mathrm{NaOH}, \\
\text { reflux for } 8 \mathrm{hrs} \text { at } \\
60 \mathrm{C}^{\mathrm{C}}\end{array}$ & 5.103 & 5.615 & $20 \%$ & Unstable \\
\hline $\begin{array}{l}\text { Neutral } \\
\text { Water(DM), } \\
\text { reflux for } 8 \text { hour } \\
\text { at } 100^{\circ} \mathrm{C}\end{array}$ & 5.054 & 5.602 & $35 \%$ & Unstable \\
\hline $\begin{array}{l}\text { Oxidation } \\
50 \% \mathrm{H} 2 \mathrm{O} 2 \\
\text { for } \\
48 \mathrm{hrs}\end{array}$ & 5.025 & -- & $0.0 \%$ & Stable \\
\hline $\begin{array}{l}\text { Dry Heat } \\
\text { Kept in oven at } \\
60 \text { o for } 48 \mathrm{hrs}\end{array}$ & 5.014 & -- & $0.0 \%$ & Stable \\
\hline $\begin{array}{l}\text { Photo Stability } \\
\text { Exposed to direct } \\
\text { sunlight for } 48 \mathrm{~h}\end{array}$ & 5.021 & 5.802 & $30 \%$ & Unstable \\
\hline
\end{tabular}




\section{Conclusion}

The stability study of Naratriptan HCL was performed under acidic, basic, neutral, photolytic, and dry heat. The drug was found to be unstable in alkaline medium as well as acidic medium compared to neutral conditions. The drug showed degradation in $8 \mathrm{hr}$ at $60^{\circ} \mathrm{C}$ when the studies were carried under $0.01 \mathrm{~N} \mathrm{NaOH}$, while drug showed the degradation in $0.01 \mathrm{~N} \mathrm{HCl}$ when it was subjected to reflux for 2 hours at $60^{\circ} \mathrm{C}$. Same retention time of degradant was also observed in neutral conditions, when drug was allowed to reflux in water for 8 hours at $100^{\circ} \mathrm{C}$. Drug was found to be stable in 50\% $\mathrm{H} 2 \mathrm{O} 2$. Drug was also found to be stable in other conditions such as photolytic and dry heat. Suitable mobile phase was developed and separation of drug and degradant was achieved using isocratic elution. The method was developed on C-18 column using acetonitrile: water as a mobile phase in the ratio of 50:50, the selected wavelength was 223 $\mathrm{nm}$ and flow rate was $1 \mathrm{ml} / \mathrm{min}$.

Conflicts of Interest: “The authors declare no conflict of interest."

\section{References}

1. British Pharmacopoeia, Stationery Office London Publication 2003, Vol.1, 465-4662.

2. Ahuja, S.; Stephen, S. Handbook of Modern Pharmaceutical Analysis, Pg no. 86-167, 445482.

3. Reynolds, D. Available guidance and best practices for conducting forced degradation studies. Pharm. Tech. 2002.

4. Jenke, D. Chromatographic method validation: A review of current practices and procedure guidelines for primary validation parameters. J. Liq. Chromatogr. 1996, 19, 737757.

5. Smith, D. best practices for conducting forced degradation studies. Pharm. Tech. 2002.

6. Sethi, P. High Performance liquid Chromatography, Quantitative Analysis of Pharmaceutical Formulation, p 4-15.

7. Indian Pharmacopoeia, Government of India, Ministry of health and family welfare, Published by controller of Publications, New Delhi, 1996, Vol I and II, A-80

Submitted for possible open access publication under the terms and conditions of the Creative Commons Attribution (CC BY) license 2017 by the authors (http://creativecommons.org/licenses/by/4.0/). 